\title{
Properties of the HPHT diamond when used as a soft X-Ray detector
}

\author{
Rodrigo Meléndrez-Amavizca', Mercedes Díaz-Lagos², Segundo Agustín Martínez-Ovalle²,* \\ ${ }^{1}$ Departamento de Investigación en Física, Academia de Física de Radiaciones, \\ Universidad de Sonora, Hermosillo, Sonora, México \\ ${ }^{2}$ Grupo de Ingeniería Geológica, Universidad Pedagógica y Tecnológica de Colombia, Sogamoso, Colombia
}

\begin{abstract}
The diamond has extraordinary physical and chemical properties. This material by having a Zeff (atomic numbercash) equivalent to the human tissue is converted into a material suitable for use as a dosimeter of radiation. In this work, the properties of response to Afterglow (AG), Thermoluminescence (TL) and Optically Stimulated Luminescence (OSL) in HPHT diamond type lb (high temperature and high pressure diamond) are studied when subjected to lightning X $(0.75 \mathrm{~mA}, 35 \mathrm{kV})$. The properties dosimetric curve and the TL were obtained on a computer Riso TL/OSL, where studies of fading (fading thermoluminescent), show that after a time of 1 hour, it stabilizes the signal TL and the reproducibility presents an error signal is not greater $5 \%$. It is linearity in the three techniques for absorbed dose between 0-2 Gy. Between 2-9 Gy can be considered a response supralineal for the three techniques used and obtained a saturation of the sample to the absorbed doses increased to 9 Gy. It is showed that this material presents a promising future as a dosimeter in clinical radiation beams soft, used especially for radiation dosimetry for clinical use. (C) 2017. Acad. Colomb. Cienc. Ex. Fis. Nat.
\end{abstract}

Key words: Properties dosimetric; Characteristics of the TL and OSL; Diamond; High pressure; High temperature.

Propiedades del diamante HPHT cuando es usado como detector de rayos $\mathrm{x}$ de baja intensidad

\section{Resumen}

El diamante posee extraordinarias propiedades físicas y químicas, y se ha propuesto para ser utilizado como dosímetro de radiación por tener un Zeff equivalente al tejido humano. En este trabajo, se estudian las propiedades de respuesta al Afterglow (AG), la termoluminiscencia (TL) y la luminiscencia ópticamente estimulada (OSL) en materiales diamante HPHT tipo lb, cuando son sometidos a Rayos X suaves (0,75 mA, $35 \mathrm{kV})$. Las propiedades dosimétricas y la curva TL fueron obtenidas en un equipo Riso TL/OSL, donde los estudios de fading, muestran que luego de 1 hora se estabiliza la señal de TL, la reproducibilidad presenta un error en señal no mayor 5\%. Se encuentra linealidad en las tres técnicas para dosis absorbida entre 0-2 Gy, entre 2-9 Gy puede considerarse una respuesta supralineal para las tres técnicas obteniendo una saturación de la muestra a dosis absorbidas mayores de 9 Gy. Se demuestra que este material presenta un futuro prometedor como dosímetro clínico para haces de radiación suaves, usados particularmente para dosimetría de radiaciones de uso clínico. (c) 2017. Acad. Colomb. Cienc. Ex. Fis. Nat.

Palabras clave: Propiedades dosimétricas; Características TL y OSL; Diamante; Alta Presión; Alta temperatura.

\section{Introduction}

Currently, a good number of new techniques for the treatment of cancer, such as intensity-modulated radiation therapy, radiotherapy, helical, radiosurgery, radiotherapy, stereotactic, RapidArc and other, giving rise to deposit a high radiation dose in small fields Taylor, et al., 2011. This type of treatment requires an in vivo dosimetry in real time (IV/TR). Currently, among the available technologies for dosimetry IV/TR, we can mention the ionization chamber diodes and detectors diamond, but the cameras are not used for dosimetry in-vivo due to its fragility, its large size and the need for electrical connections with high voltage. Diodes are used frequently for dosimetry IV/TR, but its answer presents fluctuations with temperature and accumulated dose. In addition, as its response is not equivalent to the soft tissue is necessary restricts them to increase the size of the device, so that its use in certain types of dosimetry, where you have rather small fields is not desirable Spasic, et al., 2011; Morin, et al., 2013.

*Corresponding autor:

Segundo Agustín Martínez-Ovalle, s.agustin.martinez@uptc.edu.co

Received: February 22, 2017

Accepted: June 05, 2017 
A large number of materials with features luminescent have been studied recently Santiago, et al., 2011; Molina, et al., 2012; Guarneros, et al., 2013; Marcazzo, et al., 2015, with new techniques. Most of these materials tend to exhibit a sub-or over-response compared with the absorbed dose deposited in tissue, because these materials are not tissueequivalent $(\mathrm{Te})$ (Zeff $\approx 7.4$ ). This aspect, entails that such composite materials behave in front of the radiation of a variety of ways to interact with the treated tissue, making it difficult for direct application in radiation therapy, a procedure widely used today for the treatment of cancer, if not the most common, and of special interest in the application of these devices. Recently, the synthetic diamond grown by the technique of high-pressure and high-temperature (HPHT) has been proposed as a detector of ionizing radiation Low, $\boldsymbol{e t}$ al., 2011; Meléndrez, et al., 2006; Chernov, et al., 2013; Gil et al., 2014; Gil et al., 2015. The importance of this material lies in its physical and chemical properties, as it has a Zeff $=6$ (atomic number-cash) equivalent to the human tissue, this is a relevant feature in a dosimeter for radiation therapy. In addition, this material is not toxic and it is hard to radiation, provides a high spatial resolution and presents a dependency with the dose rate. By these features, it is considered as a dosimeter with great perspective, the reason for which is studied in this work.

The dosimetric properties and characteristics of the brightness curve of the HPHT diamond are studied by the techniques of thermoluminescence (TL) and optically stimulated luminescence (OSL). The TL that exhibits the diamond was reported initially by the chemist Sir Robert Boyle in 1663, the closer a diamond is to the body and to observe the emission of light with their own eyes in the dark Chen \& Kirsh, 1981. The brightness curve of the TL was studied with models of energy bands for the luminescence in solid materials, with which it is observed the efficiency and the activation energies of traps present in the material due to impurities in its crystal lattice, generated by the rupture in the periodicity of the crystal structure and makes it possible for electrons to possess energies which are forbidden in the perfect crystal Furetta, 2013; Mckeever, 1985; Oberhofer \& Scharmann, 1993. On the other hand, the OSL is done in this work to observe the advantages of using optical stimulation in comparison with the thermal stimulation. The main advantage of OSL over TL is that measurements can be performed in situ and in vivo and in real time Yukihara \& Shephen, 2011.

In this work the TL and OSL curves obtained in the Riso TL / OSL model DA-20 are studied, with the previous exposure of the HPHT type lb synthetic diamond to ionizing radiation with a "soft" X-ray tube with photons of $35 \mathrm{KeV}$ at a dose rate of $0.624 \mathrm{~Gy} \cdot \mathrm{s}^{-1}$. The results obtained in this work have a very high chance to be applied in dosimetry in situ, in vivo and in real time, applying the technique of OSL, for their potential applications in medical diagnostics with ionizing radiation such as radiotherapy Meléndrez, et al., 2006; Bos, 2007.

\section{Materials and methods}

The synthetic HPHT type lb (Sumicrystal, UP-3510) was purchased from ProDiamond, Germany. This diamond is a single crystal with dimensions of $3.5 \cdot 3.5 \cdot 1 \mathrm{~mm}^{3}$, which is performed by a heat treatment of $800{ }^{\circ} \mathrm{C}$ for one hour in an atmosphere of Nitrogen. The synthesis technique of HPHT diamond is based on the growth of films from graphite, which are obtained by applying a hydrostatic pressure of hundreds of kbar at a temperature of the order of $1700{ }^{\circ} \mathrm{C}$ on graphite substrate controlling the time (these parameters will define The thickness of the film). The Diamond type $\mathrm{lb}$ contains $\mathrm{N}$ atoms substitucionales isolated, with concentrations of about $40-400 \mathrm{ppm}$ of $\mathrm{N}$, where the $80 \%$ is in dispersed form and $20 \%$ in the form of aggregates of the same. In natural diamond, the concentration of $\mathrm{N}$ atoms scattered can be around $5 \cdot 10^{10} \mathrm{~cm}^{-3}$, whereas the synthetic diamond is of the order of $10^{18} \mathrm{~cm}^{-3}$.

The curves of emission of the afterglow (AG), TL and OSL, were obtained on a computer Riso TL/OSL model DA20 with a source of radiation of soft-X-ray with maximum power of $1 \mathrm{~mA}, 50 \mathrm{kV}$ and $50 \mathrm{~W}$. The voltage can be varied from 4-50 kV. When operating at maximum power, delivers a dose rate of $2 \mathrm{~Gy} \cdot \mathrm{s}^{-1}$ and when operated at its minimum power $(0.25 \mathrm{~mA}, 10 \mathrm{kV})$ is supplied to a dose rate of 10 $\mathrm{mGy} \cdot \mathrm{s}^{-1}$ Bøtter-Jensen, 2008.

With the previous exposure of synthetic HPHT type lb diamond to ionizing radiation using the "soft" X-ray tube, the irradiations were performed from an absorbed dose of 0.624 Gy to an absorbed dose of 18.72 Gy. First, it records the signal AG which is obtained at an exposure time of 300 s. The signal TL is recorded from room temperature up to $450{ }^{\circ} \mathrm{C}$. The next step is to get the signal OSL using a filter BG-39 from the stimulation of diode laser infrared (870 nm) in a time of $60 \mathrm{~s}$. In the TL curves, measurements of the activation energies of the maximum temperature peaks, the thermoluminescent fading or fading and the reproducibility of the HPHT type lb diamond were also performed.

The irradiations were performed in sequences of 0.624 to $18.72 \mathrm{~Gy}$. Once the first irradiation was completed of the sample it is read TL from room temperature to $450{ }^{\circ} \mathrm{C}$ at a heating rate of $5^{\circ} \mathrm{C} \cdot \mathrm{s}^{-1}$. Then the sample is subjected to cooling with a flow of nitrogen until they reach again the room temperature. Subsequently are available the sample to move to a different dose and is carried out the same procedure of reading to the dose prescribed.

To observe characteristics in the material due to charge carriers that can recombine at room temperature, it was performed after the irradiation, the measurement of the emission of light, called AFTERGLOW (AG), this emission of light is obtained by the photomultiplier tube at room temperature for 5 minutes). Again, a reading is taken TL in order to observe the recombination that occurred at room temperature, and to detect the light emission immediately after the irradiation. Then, it is performed the cooling for 1 minute and again irradiates the sample at the same dose to 
get the measure of the signal AG and subsequently obtain the signal of the OSL with the LED's of the infrared. The signal is observed in the photomultiplier tube for 1 minute and performs the reading TL to get the fading of TL in the two methods mentioned, as described in figure 1.

\section{Results and discussion}

In TL, exposure of the HPHT diamond to a source of radiation at room temperature $\left(\mathrm{T}_{0}\right)$ is required followed by a caloric stimulus at a temperature $\mathrm{T}>\mathrm{T}_{0}$, to obtain the brightness curve (Emission intensity as a function of temperature) that Is shown in figure 2 .

The curve exhibits three broad peaks of the TL located at $\mathrm{T} \approx 77^{\circ} \mathrm{C}$ and $\mathrm{T} \approx 337^{\circ} \mathrm{C}$, each one of them can be the result of the superposition of at least two peaks of TL, and the intensity for each peak is related to the number of charge carriers trapped and the number of defects that owns the material. It is also observed that with the increase of the applied dose, at doses $>9.984 \mathrm{~Gy}$, reached a maximum in intensity of the peaks TL, which may be associated to the saturation of the sample.

For the analysis of each one of the peaks of TL of figure 2, it was performed the analysis using these different techniques (TL, OSL, AG). For the luminescence emitted directly after the radiation, called a AG, it is found that the sample presents centers of recombination at room temperature that are related with the first peak of TL is located at $\mathrm{T} \approx 77^{\circ} \mathrm{C}$.

To perform the experiments of OSL, it is observed $\mathrm{T} \approx 239{ }^{\circ} \mathrm{C}$, is recombined by using the photo-stimulation with diode laser infrared $(870 \mathrm{~nm})$. The OSL manages to recombine all carriers of charge, but fails to recombine charge carriers to the third peak of the TL located at $\mathrm{T} \approx$ $337^{\circ} \mathrm{C}$, it was concluded then, that the peak of TL to $\mathrm{T}_{0}$ and $\mathrm{T} \approx 77^{\circ} \mathrm{C}$ are associated, to a great extent to the signal from the $\mathrm{AG}$ and the peak width of the TL located at $\mathrm{T} \approx 239^{\circ} \mathrm{C}$, is the one that contributes mainly in the emission of the OSL, leaving only the peak TL high temperature $\mathrm{T} \approx 337^{\circ} \mathrm{C}$, after the process of $300 \mathrm{~s}$ of the AG and $60 \mathrm{~s}$ of the OSL, as shown in figure 3 .

A comparison of the three techniques (TL, OSL and AG) used in this work are also shown in figure 3 and indicates the type of technique that must be used for each type of TL. The signal TL (black curve) corresponds to the irradiation with an absorbed dose of 0.624 Gy, subsequently observes the signal TL_AG (red curve) after you take the reading needle, where it can be observed the band between $30-60{ }^{\circ} \mathrm{C}$ is evicted, or faded by the recombination of charge carriers at $\mathrm{T}_{0}$ for $300 \mathrm{~s}$. third signal TL-AG/OSL (green curve) postto the AG and OSL, it can be seen that with the techniques of AG and OSL is achieved evict or to recombine most of the traps electrons close to the conduction band with the holes in the band of valence. Of these features it is inferred that these two techniques will allow the dosimetry, in-situ and invivo as reference in Yukihara \& Shephen, 2011.

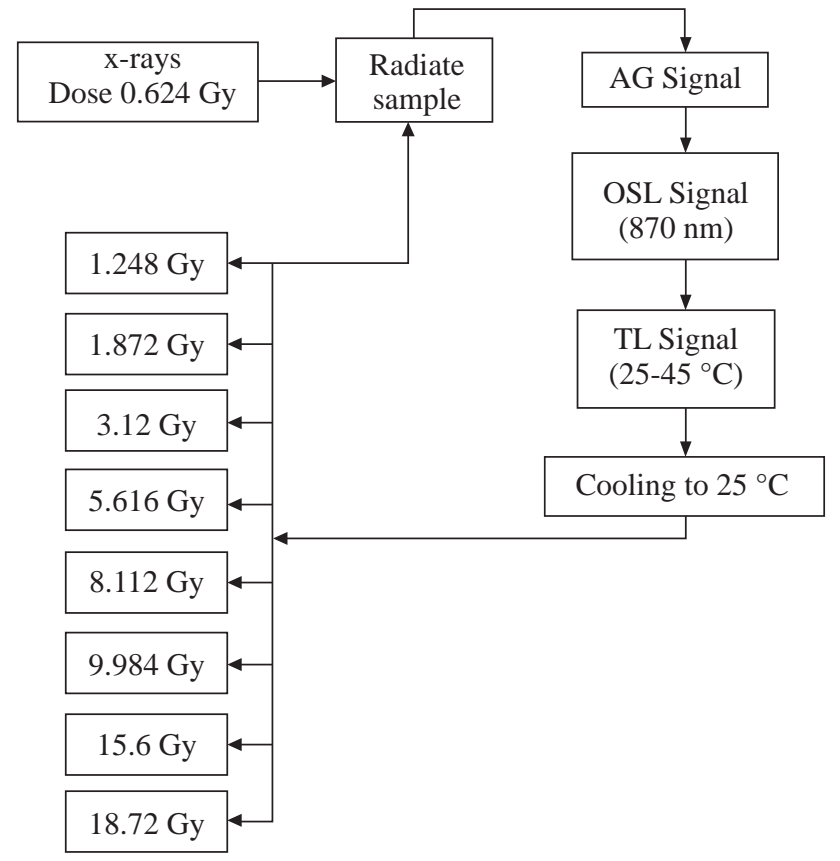

Figure 1. Diagram of the experimental procedure for obtaining the curves of AG, OSL and TL.

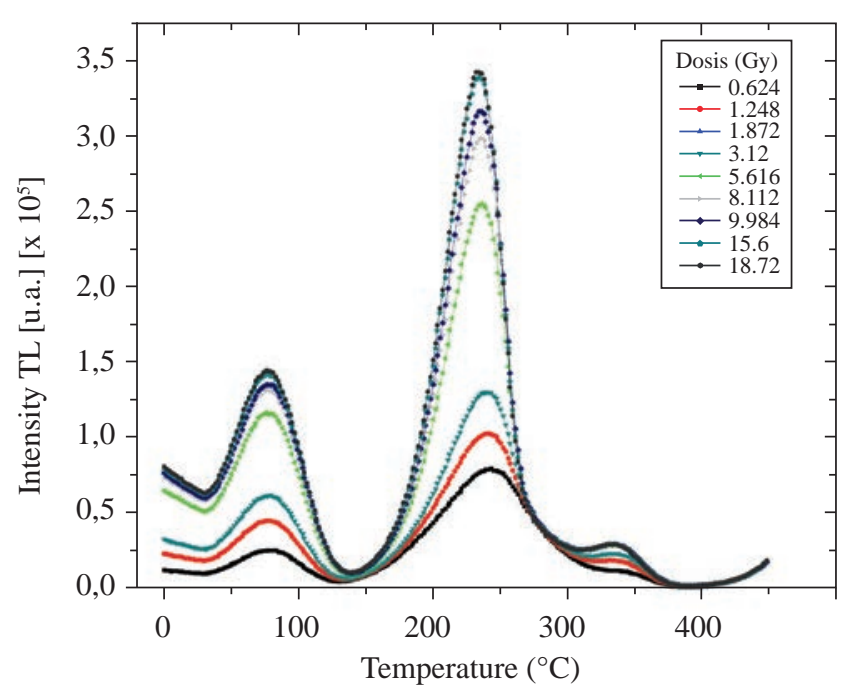

Figure 2. Curves of brightness of TL by irradiating with X-rays immediately after irradiation.

The McKeever method is widely used to determine with greater precision the number of traps present in the material dosimetry, the position of its peak in the brightness curve $\mathrm{TL}$, as the energy of activation (E) and frequency factor (s). For the analysis of the brightness curve is used this method Mckeever, 1985. Figure 4A shows the graph of maximum Temperature $\left(\mathrm{T}_{\max }\right)$ in function of the end Temperature $\left(\mathrm{T}_{\text {stop }}\right)$. In this figure, it is observing three peaks of the TL that are to be analyzed and located to temperatures of 103, 243 and $340{ }^{\circ} \mathrm{C}$, respectively, and correspond to a first order 


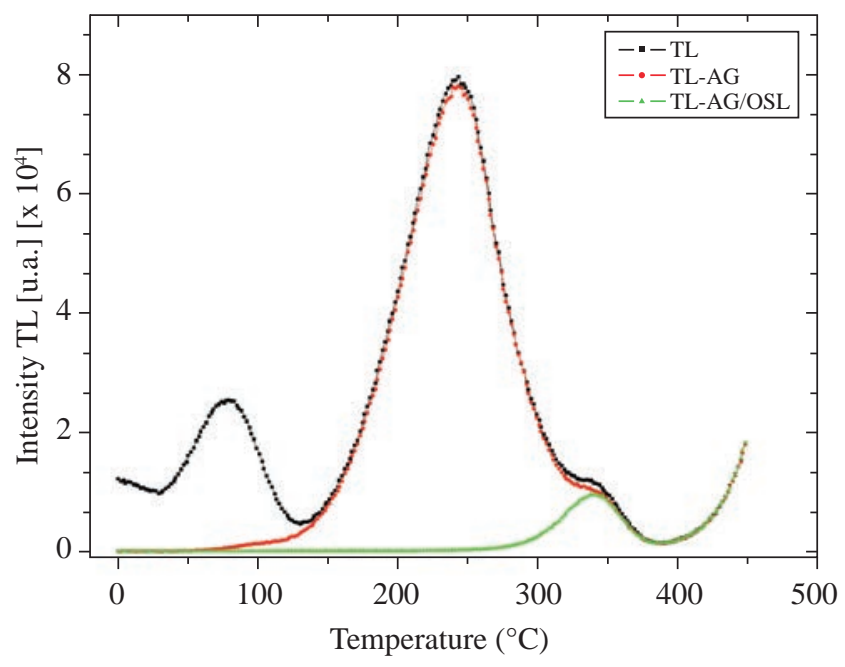

Figure 3. Comparison of the techniques TL immediately after irradiation and subsequently to the AG and TL, at a dose of $0.624 \mathrm{~Gy}$.
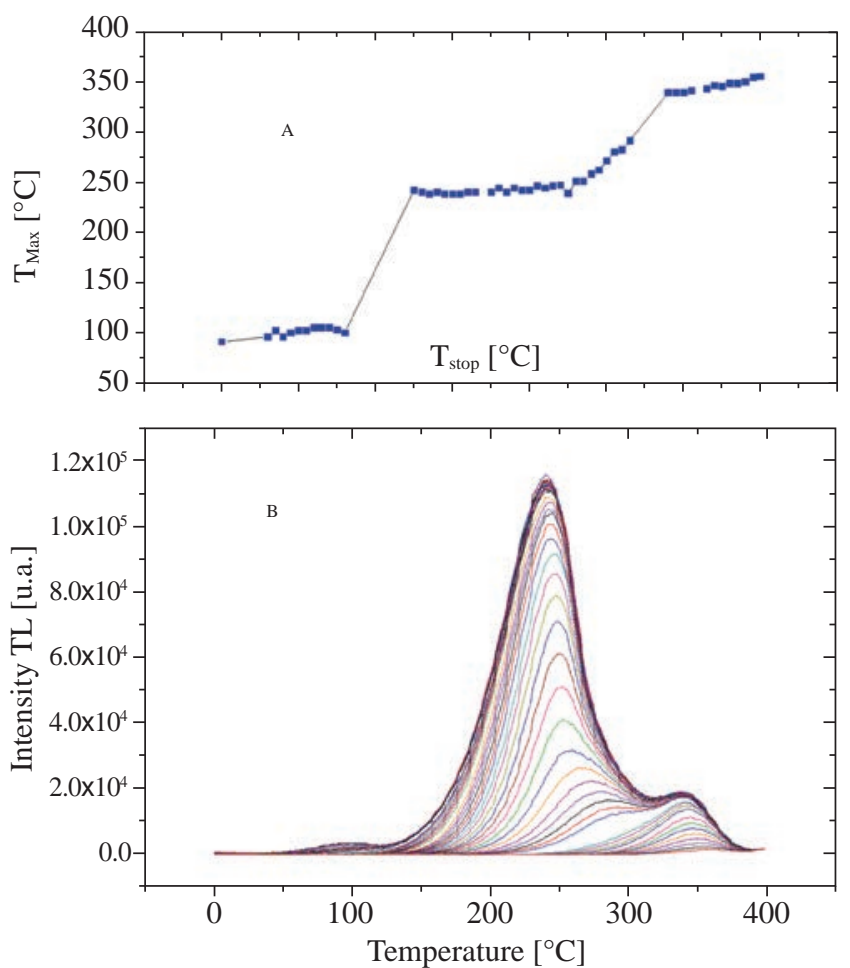

Figure 4. Analysis of the TL brightness curve by the Mckeever method after irradiation with X-rays at a dose of $1.872 \mathrm{~Gy}$.

kinetics, that is to say, that the electrons released by stimulus heat transfer from the trap to the conduction band, and these subsequently recombine immediately with a hole by emitting a photon. Therefore, the re-entrapment of the charge carriers is negligible during the heating process of the sample of diamond for these three peaks. In figure 4B, the curve TL can be associated to four peaks with different energies of activation and frequency factor whose values are reported in Table 1. In addition, it was observed that in the region between $250-290{ }^{\circ} \mathrm{C}$ appears another peak of TL which may be related to defects in the sample.

After analyzing and exposing the TL properties of the HPHT type lb diamond when subjected to X-rays, the dosimetric properties of the diamond were studied. For this, their response to the dose for the AG, OSL and TL techniques was analyzed. Each of the curves was studied between the different ranges of absorbed dose to establish the ranges in which it can be considered linear, supralineal or infralineal if it exists.

Figure 5 shows the dose range for which the diamond dosimeter can be considered linear. For this case, the values correspond respectively to a dose of up to $\approx 2$ Gy and the values of the correlation factors are: $\mathrm{AG}=0.99959, \mathrm{OSL}=$ 0.99984 and $\mathrm{TL}=0.99906$.

Figure 6 shows the range of dose to which the dosimeter of diamond can be considered supralineal. In this case it is observed that can be considered supralineal up to $\approx 9 \mathrm{~Gy}$. The values of the correlation factors correspond to: $\mathrm{AG}=0.99825$, OSL $=0.99273$ and $\mathrm{TL}=0.99968$.

From the above results and observing figure 7 , it can be concluded that the sample of HPHT diamond type lb presents a dose range for which the answer is linear, another range for which the response is supralineal and presents a saturation level a absorbed dose greater than 9 Gy.

Table 1. Experimental determination of the activation energy factors and frequency factor of each trap for the HPHT diamond subjected to X-rays.

\begin{tabular}{lcccc}
\hline & Pk1 & Pk2 & Pk3 & Pk4 \\
\hline $\mathrm{E}(\mathrm{ev})$ & 0.623 & 0.792 & 1.476 & 1.883 \\
$\mathrm{~T}(\mathrm{~K})$ & 103 & 243 & 287 & 340 \\
$\mathrm{~b}$ & 2 & 1.003 & 1.151 & 1.519 \\
$\mathrm{~s}\left(\mathrm{~s}^{-1}\right)$ & $5.24 \cdot 10^{7}$ & $1.23 \cdot 10^{7}$ & $5.12 \cdot 10^{12}$ & $1.17 \cdot 10^{15}$ \\
\hline
\end{tabular}

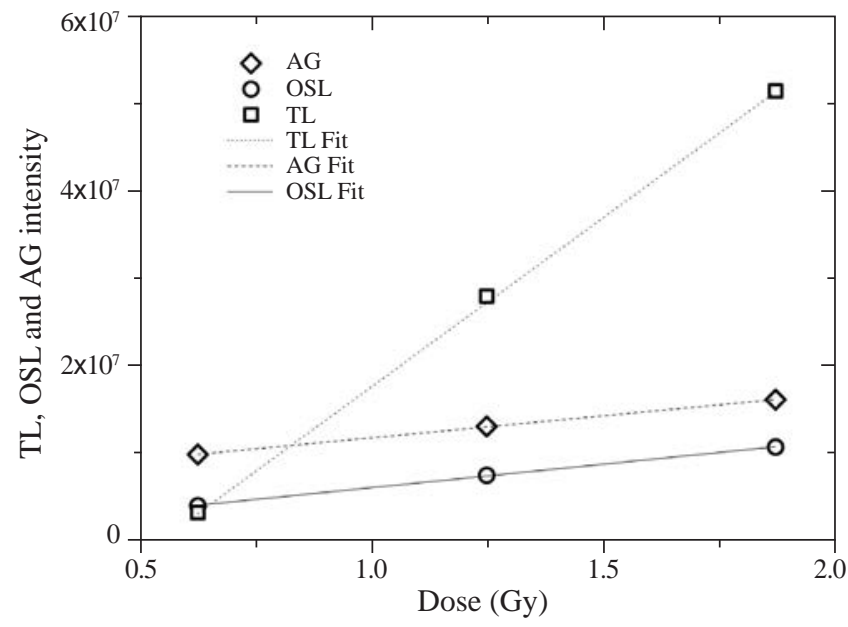

Figure 5. Linear behavior of the HPHT type lb diamond sample 


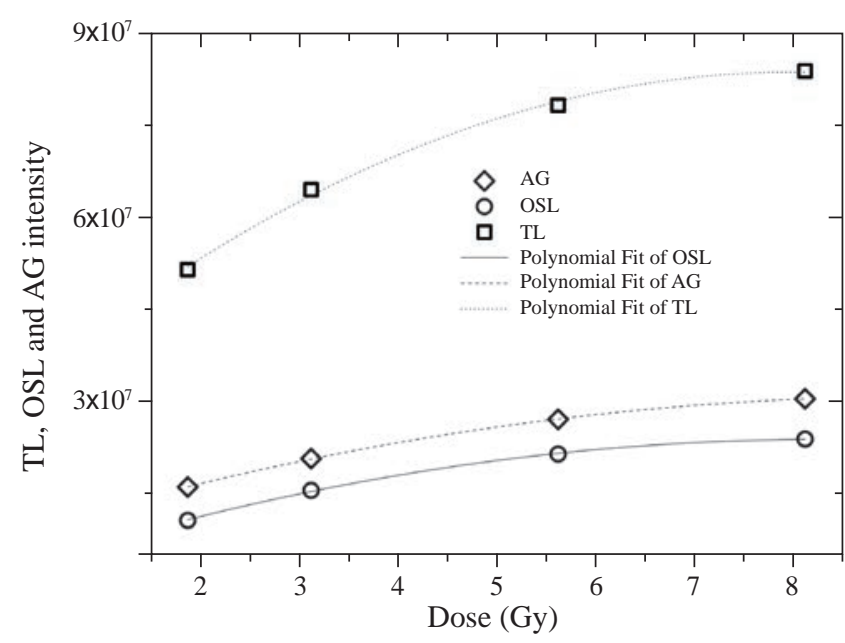

Figure 6. Supralineal behavior of the HPHT type lb diamond sample

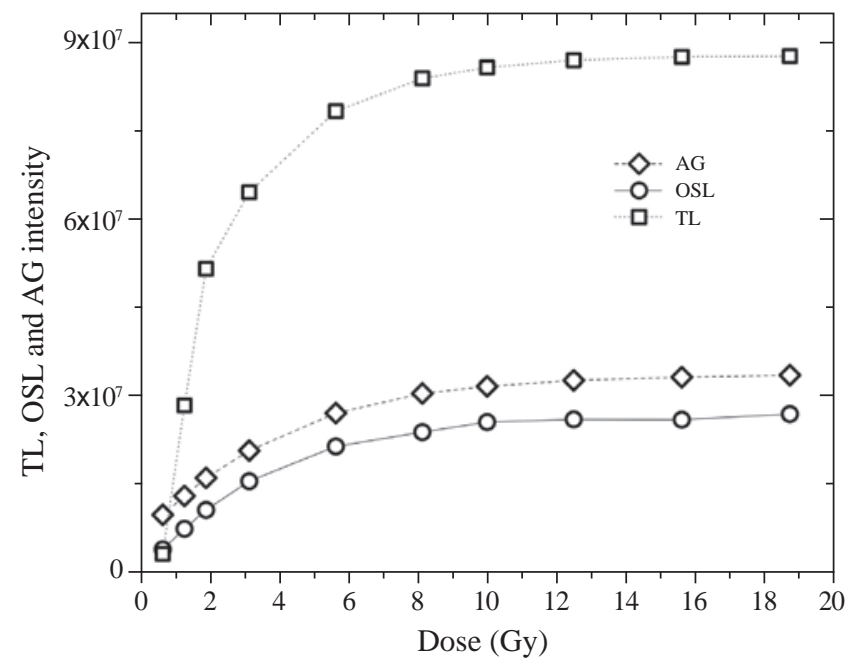

Figure 7. AG, TL and OSL dosimetry of the HPHT type Ib diamond as a function of the exposed dose of 0.624-18.72 Gy.

It was studied the fainting or fading of the signal TL postradiation in a 24-hour period, which is shown in figure 8 . During this time period, it was determined that in the first hour of the fading, the signal presents a loss of intensity of $60 \%$. In the graphic inserted, it is noticed that this fall is associated to the peaks of ambient temperature and the peak located at $77^{\circ} \mathrm{C}$, after an hour the fading of the signal is only $1 \%$.

Finally, the sample of diamond was subjected to ten continuous cycles of exposure to radiation and the electrical signals AG, OSL and TL at a dose of $1.87 \mathrm{~Gy}$. This process is performed in order to ensure the reproducibility in the signal with a percentage error of $5 \%$.

\section{Conclusion}

In dosimetry of clinical dosimeters used must comply with important features for the estimation of the absorbed dose, one of them is the accuracy, which is related to the uncertainty

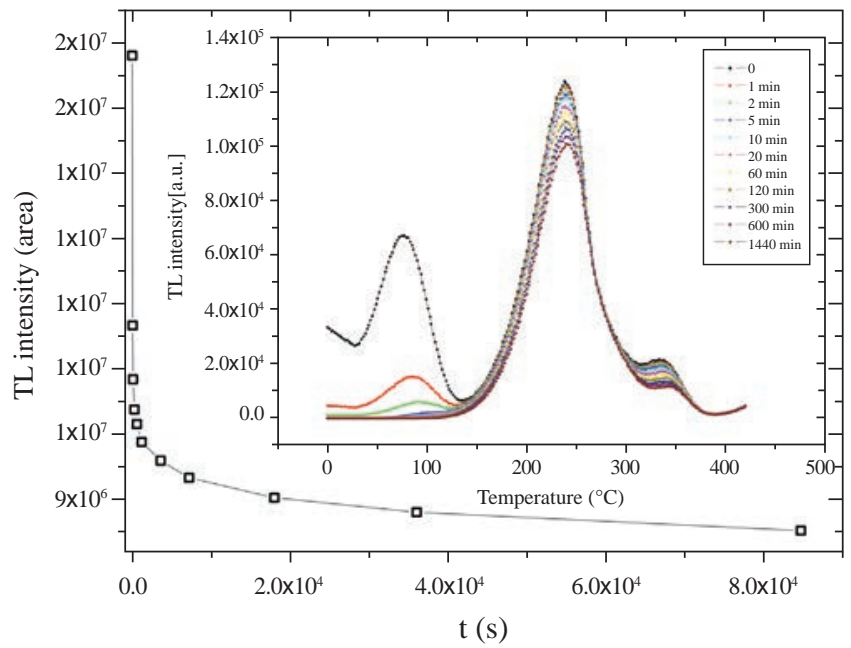

Figure 8. Decay of the TL signal, for a waiting time of 24 hours.

of random associated to the measure and refers to the statistical method applied to a number of measures. The detector of Diamond is considered to be a detector of high precision and accuracy, this is contrasted with the reproducibility of the sample that presents a behavior in the signal characterized by a TL of (0.35\%), a NEEDLE (4.25\%) and a OSL (0.33\%). These parameters obtained for the Diamond, it allowed to infer that this material in the future can be used as a dosimeter in clinical high accuracy.

The phenomenon of TL may be observed in many materials, however, only a few meet the requirements to be used in dosimetry clinic, with this work we show that for radiation beams of low energy, it is also an excellent material dosimetry.

It is observed that the sample presents a signal AG due to the peak of the TL located at room temperature and at $77^{\circ} \mathrm{C}$, which recombines at room temperature and decays in $300 \mathrm{~s}$. These features are ideal in dosimetry.

The TL is composed of at least 3 peaks widths of TL located around 77,239 and $337^{\circ} \mathrm{C}$, according to experiments obtained by the method of McKeever.

Studies of fading, after 1 hour have stability in the signal of TL, being the peak of $92{ }^{\circ} \mathrm{C}$ responsible for this decay.

It was determined that the HPHT diamond type lb sample has values in a dose range where a linear response, supralineal and a saturation level at absorbed doses higher than 9 Gy appear.

\section{Conflicts of interest}

The authors declare that they have no conflict of interest.

\section{References}

Taylor, M. L., Kron, T., Franich, R. D. (2011). A contemporary review of stereotactic radiotherapy: Inherent dosimetric complexities and the potential for detriment. Acta Oncologica. 50 (4): 483-508. 
Spasic, E., Magne, S., Aubineau-Lanièce, I., De Carlan, L., Malet, C., Ginestet, C., Ferdinand, P. (2011, June). Intracavitary in vivo dosimetry based on multichannel fiber-coupled Radioluminescence and Optically Stimulated Luminescence of Al 2 O 3: C. In Advancements in Nuclear Instrumentation Measurement Methods and their Applications (ANIMMA), 2011 2nd International Conference on (pp. 1-6). IEEE.

Morin, J., Béliveau-Nadeau, D., Chung, E., Seuntjens, J., Thériault, D., Archambault, L., Beaulieu, L. (2013). A comparative study of small field total scatter factors and dose profiles using plastic scintillation detectors and other stereotactic dosimeters: the case of the CyberKnife. Medical Physics, 40 (1).

Santiago, M., Marcazzó, J., Grasselli, C., Lavat, A., Molina, P., Spano, F., Caselli, E. (2011). Thermo-and radioluminescence of undoped and Dy-doped strontium borates prepared by solgel method. Radiation Measurements. 46 (12): 1488-1491.

Molina, P., Santiago, M., Marcazzó, J., Spano, F., Henniger, J., Cravero, W., Caselli, E. (2012). Radioluminescence of red-emitting Eu-doped phosphors for fiberoptic dosimetry. Applied Radiation and Isotopes. 71: 12-14.

Guarneros-Aguilar, C., Cruz-Zaragoza, E., Marcazzó, J., Palomino-Merino, R., Espinosa, J. E. (2013, July). Synthesis and TL characterization of Li 2 B 4 O 7 doped with copper and manganese. In C. Vázquez-López, G. Espinosa-García, \& J. I. Golzarri (Eds.), AIP Conference Proceedings (Vol. 1544, No. 1, pp. 70-77). AIP.

Marcazzó, J., Camargo, L., Khaidukov, N. M., Santiago, M. (2015). Study of optically stimulated luminescence of Tb 3+/Sm 3+ doubly doped K 2 YF 5 single crystals. Journal of Luminescence. 164: 112-115.

Low, D. A., Moran, J. M., Dempsey, J. F., Dong, L., Oldham, M. (2011). Dosimetry tools and techniques for IMRT. Medical Physics. 38 (3): 1313-1338.

Melendrez, R., Schreck, M., Chernov, V., Preciado-Flores, S., Pedroza-Montero, M., Barboza-Flores, M. (2006).
Afterglow, TL and IRSL in beta-irradiated HPHT type Ib synthetic diamond. Physica Status Solidi (a). 203 (12): 3167-3172.

Chernov, V., Meléndrez, R., Gastélum, S., Pedroza-Montero, M., Piters, T., Preciado-Flores, S., Barboza-Flores, M. (2013). Afterglow and thermoluminescence properties in HPHT diamond crystals under beta irradiation. Physica Status Solidi (a). 210 (10): 2088-2094.

Gil-Tolano, M. I., Meléndrez, R., Lancheros-Olmos, J. C., Castaneda, B., Soto-Puebla, D., Chernov, V., PedrozaMontero, M., Barboza-Flores, M. (2014). AG, TL, and IRSL dosimetric properties in X-ray irradiated HPHT diamond crystals. Physica Status Solidi (a). 211 (10): 23592362.

Gil-Tolano, M. I., Meléndrez, R., Lancheros-Olmos, J. C., Castaneda, B., Soto-Puebla, D., Chernov, V., PedrozaMontero, M., Barboza-Flores, M. (2015). Thermoluminescence studies on HPHT diamond crystals exposed to $\beta$-irradiation. Physica Status Solidi (a). 212 (11): 2507-2511.

Chen, R., Kirsh, Y. (2013). The analysis of thermally stimulated processes. Elsevier.

Furetta, C. (2010). Handbook of thermoluminescence. World Scientific.

McKeever, S. W. (1988). Thermoluminescence of solids (Vol. 3). Cambridge University Press.

Oberhofer, M., Scharmann, A. (Eds.). (1993). Techniques and management of personnel thermoluminescence dosimetry services (Vol. 2). Springer Science \& Business Media.

Yukihara, E. G., McKeever, S. W. (2011). Optically stimulated luminescence: fundamentals and applications. John Wiley \& Sons.

Bos, A. J. J. (2006). Theory of thermoluminescence. Radiation Measurements, 41: S45-S56.

[19] Bøtter-Jensen, L. (2008). Guide to Riso the Riso TL/OSL Reader. Riso National Laboratory, Denmark. 